\title{
JAHNS, Sigrid, Das Reichskammergericht und seine Richter. Verfassung und Sozialstruktur eines höchsten Gerichts im Alten Reich. Teil II : Biographien
}

Christophe Duhamelle

\section{OpenEdition}

Édition électronique

URL : http://journals.openedition.org/ifha/1033

DOI : $10.4000 /$ ifha. 1033

ISSN : 2198-8943

Éditeur

IFRA - Institut franco-allemand (sciences historiques et sociales)

Référence électronique

Christophe Duhamelle, "JAHNS, Sigrid, Das Reichskammergericht und seine Richter. Verfassung und Sozialstruktur eines höchsten Gerichts im Alten Reich. Teil II : Biographien », Revue de I'IFHA [En ligne], Date de recension, mis en ligne le 01 janvier 2004, consulté le 22 septembre 2020. URL : http:// journals.openedition.org/ifha/1033 ; DOI : https://doi.org/10.4000/ifha.1033

Ce document a été généré automatiquement le 22 septembre 2020.

(CIFHA 


\title{
JAHNS, Sigrid, Das
}

\section{Reichskammergericht und seine} Richter. Verfassung und Sozialstruktur eines höchsten Gerichts im Alten Reich. Teil II : Biographien

\author{
Christophe Duhamelle
}

On attendait depuis longtemps la publication complète des travaux qui avaient permis à S.J. (professeure à l'université de Munich) d'obtenir l'habilitation en 1990/91. Plusieurs fois repoussée, constamment complétée, l'entreprise débute par ces deux forts volumes renfermant les biographies de 128 juristes dont 92 ont été véritablement assesseurs au Tribunal de la Chambre Impériale et 36 y ont été présentés, mais n'ont pu satisfaire aux conditions d'admission. L'ouvrage couvre la période 1740-1806 et comprend également tous ceux qui étaient déjà en poste en 1740 ; il concerne donc uniquement la phase finale du tribunal, alors installé à Wetzlar, près de Francfort-surle-Main. Chaque biographie présente avec une grande précision les éléments personnels (dont les anoblissements), les connexions familiales, l'origine et la formation, la carrière précédant et (éventuellement) suivant l'activité au tribunal, les écrits de chaque assesseur. Les notices sont classées selon les présentations : le personnel juridique du Tribunal de la Chambre Impériale (contrairement à celui de l'autre grand tribunal d'Empire, le Conseil Impérial Aulique, sis à Vienne et nommé par l'empereur) était en effet présenté, avant d'être accepté sur des critères professionnels, par les princes-électeurs, l'empereur et les Cercles d'Empire avec, pour certains, une alternance confessionnelle dans le droit de présentation. Des index liminaires, et surtout un CD-Rom joint à l'ouvrage, permettent de s'y retrouver. L'ensemble constitue une somme d'informations considérable qui sera suivie d'un volume d'analyse globale dont on espère qu'il donnera toute sa mesure à une recherche répondant à un véritable besoin. 
2 En effet, les tribunaux d'Empire constituaient l'institution la plus importante du SaintEmpire en tant que tel, " au-dessus » des États territoriaux. La littérature déjà nombreuse à ce sujet (et dont la «Librairie allemande » s'est amplement fait l'écho) ne cesse de souligner leur médiation entre les territoires, le refuge que trouvent auprès d'eux les sujets soumis aux innovations des princes, le rôle conservateur qu'ils ont joué pour le maintien des petits états d'Empire face à l'appétit des grandes principautés, la masse des affaires traitées (plusieurs dizaines de milliers). On sait aussi quelle influence ces tribunaux (fondés en 1495 pour la Chambre Impériale, en 1498 pour le Conseil Aulique) ont exercée sur la construction institutionnelle des justices territoriales, à qui ils ont servi de modèle. Maints exemples individuels ont enfin mis en lumière le rôle central joué par les juristes de ces instances dans l'émergence d'une élite technique et politique impériale qui tient ensuite souvent le premier registre à l'échelon territorial et anime le débat sur la réforme de l'Empire et de ses composantes, jusqu'au XVIIIe s., où cette élite déploie son activité la plus grande. Mais on ne disposait pas jusqu'à présent des connaissances nécessaires pour évaluer vraiment l'impact de ces institutions - et surtout celui de la Chambre Impériale, vouée par son mode de désignation à être une pépinière de talents pour toutes les régions de l'Empire.

3 C'est désormais chose faite ; mais on laissera à S.J. elle-même, dans son prochain volume synthétique, le soin de détailler le résultat.

Christophe DUHAMELLE (MHFA) 